\title{
EL PAPEL DE LA AUTORÍA EN LA MEDIACIÓN DE LOS PROCESOS DE ENSEÑANZA-APRENDIZAJE EN LAS UNIDADES DIDÁCTICAS DE LA EDUCACIÓN A DISTANCIA
}

THE ROLE OF THE AUTHOR IN THE MEDIATION PROCESS IN TEACHING-LEARNING TEACHING UNITS OF DISTANCE EDUCATION

\section{Volumen 12, Número 3}

Setiembre-Diciembre

pp. 1-16

Este número se publicó el 30 de setiembre de 2012

Patricia Gómez-Figueroa

Revista indizada en REDALYC

Revista distribuida en las bases de datos:

CATÁLOGO DE LATINDEX, IRESIE, $\underline{\text { CLASE}}, \underline{\text { DIALNET, DOAJ, E-REVIST@S, }}$

Revista registrada en los directorios:

ULRICH'S, $\underline{\text { REDIEE}}$ RINACE, OEI, MAESTROTECA, PREAL, CLASCO

Los contenidos de este artículo están bajo una licencia Creative Commons 


\title{
EL PAPEL DE LA AUTORÍA EN LA MEDIACIÓN DE LOS PROCESOS DE ENSEÑANZA-APRENDIZAJE EN LAS UNIDADES DIDÁCTICAS DE LA EDUCACIÓN A DISTANCIA

\author{
THE ROLE OF THE AUTHOR IN THE MEDIATION PROCESS IN TEACHING-LEARNING \\ TEACHING UNITS OF DISTANCE EDUCATION
}

\section{Patricia Gómez-Figueroa ${ }^{1}$}

\begin{abstract}
Resumen: En este artículo se analiza el papel de la autoría en los procesos de enseñanza aprendizaje en la escritura de las unidades didácticas a distancia. Se presentan las definiciones de educación a distancia, sus fundamentos y cómo es la elaboración de unidades didácticas realizadas en la Dirección de Producción de Materiales Didácticos de la UNED. Para esta investigación, se entrevistó a 27 personas autoras internas y externas de la UNED y a 10 personas productoras académicas con el fin de analizar el conocimiento del autor universitario y su aplicación en la escritura científica de los materiales impresos de la UNED. Se concluye que el éxito de los aprendizajes del estudiantado de educación a distancia, mediante las unidades didácticas impresas, es gracias al conocimiento del autor y autora de su propia disciplina y a su habilidad para transmitirlo por medio de diferentes estrategias didácticas (actividades de aprendizaje, preguntas insertadas, ilustraciones, organizadores, redes semántica y, mapas conceptuales, entre otros) que garanticen el alcance de los objetivos de aprendizaje propuestos para cada curso.
\end{abstract}

Palabras clave: AUTOR, UNIDAD DIDÁCTICA, EDUCACIÓN A DISTANCIA, ESTRATEGIA DIDÁCTICA, COSTA RICA

Abstract: This paper analyzes the role of authorship in the teaching-learning process in the writing of distance learning units. It presents distance education bases, how to do distance education and how is the development of teaching units made in the Department of Instructional Materials Production of UNED. To perform this research, 27 authors (internal and external) and 10 publishers of UNED were interviewed to analyze the author's knowledge university and its application in scientific writing of printed materials at the UNED. It concludes that the success of student learning in distance education, throughout teaching units printed, is thanks to the author's knowledge of their own discipline and their ability to share it using different teaching strategies (learning activities, inserted questions, illustrations, organizers, semantic network and concept maps, etc.), in order to ensure the scope of learning objectives for each course.

Key words: AUTHOR, INSTRUCTIONAL UNIT, DISTANCE LEARNING, TEACHING STRATEGY

\footnotetext{
${ }^{1}$ Editora académica de la Universidad Estatal a Distancia, Costa Rica. Máster en Ecología y Fisiología Vegetal de la Universidad de Costa Rica.
}

Dirección electrónica:pgomez@uned.ac.cr

Artículo recibido: 26 de abril, 2012

Aprobado: 20 de setiembre, 2012 


\section{Introducción}

En la enseñanza a distancia, el estudiantado debe apropiarse del conocimiento con autonomía e independencia para entender y juzgar la realidad. Para este fin, el sistema tiene que facilitar las herramientas didácticas a cada estudiante equilibrando sus necesidades educativas y asimilando las nuevas dimensiones socioculturales, políticas y económicas y convertirse en generador de conocimiento en su entorno (Del Mastro, 2003 y Holmberg, 1995).

La Universidad Estatal a Distancia (UNED) utiliza la unidad didáctica como medio básico para impartir y administrar la enseñanza y facilitar el aprendizaje del estudiantado. En este tipo de educación a distancia, la unidad didáctica es un texto que se planea y elabora para que el educando logre los aprendizajes previstos y planificados en el programa de la asignatura y especificados al organizar la instrucción, sin necesidad de asistir a lecciones en un lugar y a una hora determinada (UNED, 1982).

De esta manera, la unidad didáctica responde al diseño curricular diseñado para cada asignatura: plantea los objetivos y contenidos para indicar qué enseñar, presenta una secuencia ordenada de actividades y contenidos para exponer cuándo enseñar, programa las actividades, la organización del espacio y del tiempo, los materiales y los recursos didácticos que revelan cómo enseñar y programa los criterios e instrumentos para la evaluación, todo en un tiempo claramente delimitado (UNED, 1982).

La unidad didáctica es una forma de planificar el proceso de enseñanza-aprendizaje alrededor de un elemento de contenido que se convierte en eje integrador del proceso, aportándole consistencia y significatividad. Esta forma de organizar conocimientos y experiencias debe considerar la diversidad de elementos que contextualizan el proceso (nivel de desarrollo del alumno, medio sociocultural y familiar, Proyecto Curricular, recursos disponibles) para regular la práctica de los contenidos, seleccionar los objetivos básicos que pretende conseguir, las pautas metodológicas con las que trabajará, las experiencias de enseñanza-aprendizaje necesarios para perfeccionar dicho proceso. (Escamilla, 1993, p. 39)

Finalmente, el objetivo fundamental de este artículo es estudiar el papel del autor o la autora, profesional especialista en la materia, al elaborar un medio didáctico, apropiado para enseñar a distancia y conforme los requerimientos de la carrera y el curso en el proceso de enseñanza aprendizaje. 


\section{Referente teórico}

\section{En busca de una definición}

Según Arends (2007) y Bruner (1997 y 1998) la educación (del latín educere, "guiar, conducir" o educare, "formar, instruir") puede precisarse como un proceso con las siguientes características:

- Complejo, multidireccional, durante el cual participan conocimientos, valores y formas de actuar.

- De vinculación cultural, moral y conductual.

- De socialización de los individuos.

- Sociocultural e histórico, pues posibilita la socialización de los sujetos y permite la continuación y el devenir cultural de las generaciones.

En nuestro caso particular, definiremos la educación a distancia como la gestión o proceso de educar o ser educado cuando este proceso autodirigido se realiza a distancia. Tal acto educativo es apoyado por el material didáctico elaborado por un equipo experimentado y multidisciplinario. Dicho proceso es el objetivo de estudio del presente artículo ${ }^{2}$.

\section{¿Cómo se lleva a cabo la educación a distancia?}

Para enviar o recibir los materiales de apoyo en la educación a distancia, existen diferentes medios electrónicos y escritos de acuerdo con las políticas de la institución y las posibilidades del estudiantado. Estos medios se clasifican en cuatro categorías:

- Voz: en esta herramienta educativa hallamos la radio, el teléfono, la audioconferencia y el correo electrónico con voz.

- Video: aquí se sitúan las imágenes fijas (presentaciones electrónicas, slides, etc.), las imágenes con movimiento filmadas (videos, películas, etc.) y las imágenes con movimiento.

- Datos: información enviada y recibida por medio de computadoras.

- Impresos: se consideran la forma fundamental de los programas de educación a distancia. Pueden ser libros de texto, guías de estudio, antologías, manuales de laboratorio, etc. Hoy algunos de los materiales impresos han sido sustituidos por

\footnotetext{
2 Lo destacado en negrita es nuestro.
} 
formatos digitales y puestos a disposición del estudiantado por medio de la internet. El educando puede estudiarlos en la Internet, pasarlos a su computadora o imprimirlos (Amador, 2001 y Williams, 2000 y 2003).

Sin embargo, el elemento clave de la educación a distancia continúa siendo el material impreso, en nuestro caso particular, la unidad didáctica. Es la herramienta per se de la educación, tal como lo afirma el novelista y semiólogo Umberto Eco, quien ha salido al paso de quienes pregonan la muerte del libro impreso, y ha dicho que ese objeto de nuestra cultura como el cinturón o el cuchillo es de tal perfección que no admite modificaciones mayores (Coover, 1992).

\section{La unidad didáctica: su elaboración}

La unidad didáctica está escrita por un equipo interdisciplinario compuesto por: autor, productor académico, encargados de cátedra, encargado de programa, especialistas, diseñadores gráficos, entre otros profesionales. En nuestro caso particular, nos enfocaremos en el papel del autor en las unidades didácticas de educación a distancia.

En el programa de Producción de Material Didáctico (Promade), al iniciar la producción de una unidad didáctica, se elige a uno o varios autores que poseen un dominio en una disciplina o campo específico de conocimiento. Ante esta definición, estaríamos en un proceso cuya finalidad es la producción de publicaciones no literarias, que se denomina edición técnica, donde se prepara un original para su publicación antes de la corrección de estilo. Según Piccolini (2002), los autores de las publicaciones técnicas no son escritores.

Así, al editar un original no literario es preciso revisarlo para asegurarse de que ese original sea correcto, esté bien organizado, se adecúe a la audiencia a la cual se dirige, cumpla con el propósito para el que ha sido escrito, sea consistente con respecto a otro capítulo del libro o a otros libros de la misma colección, no cause perjuicios al lector ni lesione la imagen de la empresa o institución (Piccolini, 2002).

En la UNED se incluyen, en esta categoría, profesionales externos e internos con derechos, obligaciones y responsabilidades iguales a las estipuladas y acordadas por la institución contratante y en apego a los alcances legales del contrato de autor y las regulaciones establecidas por la institución. El autor se designa conforme los requisitos y la 
valoración de una muestra escrita, que facilita a las instancias correspondientes determinar su idoneidad en la tarea didáctica y escrita que se le encomendará.

Por lo tanto, el autor será el profesional especialista en la materia de quien la UNED, institución contratante, demanda el servicio de elaboración de un medio didáctico (impreso, audiovisual o multimedial), apropiado para enseñar a distancia y conforme los requerimientos de la carrera y el curso.

Las funciones del autor en este proceso serían:

1. Analizar la descripción curricular.

2. Elegir una estrategia didáctica y evaluativa para desarrollar el contenido.

3. Elaborar el plan de la obra (cronograma, índice tentativo, estrategias pedagógicas) que guiarán, en líneas generales, las recomendaciones del proceso de producción de la unidad didáctica.

4. Ajustarse a las recomendaciones y sugerencias que emitan el productor, encargado de cátedra, encargado de programa y el especialista.

5. Ajustarse al modelo pedagógico de la UNED.

6. Cumplir con las entregas del material en las fechas establecidas (cronograma).

7. Entregar una obra original.

8. Firmar un contrato donde se estipulan los términos de elaboración de la obra.

9. Escoger el material de apoyo que considere necesario (gráficos, fotografías, tablas, manuales, glosarios).

\section{Metodología}

En el desarrollo de esta investigación descriptiva se recurre al método cualitativo valiéndose de una encuesta vía correo electrónico o entrevista personal (ver Anexos $\mathrm{N}$..$^{1}$ y 2) para recolectar la información.

Dicha entrevista, instrumento de recolección de datos, está estructurada por medio de un cuestionario con un conjunto de preguntas con respecto a diversas variables por medir. El estudio fue no restringido o abierto, con el fin de solicitar respuestas libres, de mayor profundidad y redactadas por el propio sujeto.

La población de estudio fueron autores(as), internos(as) o externos(as) a la UNED, de las diferentes áreas del saber:

- Ciencias de la Administración (cuatro: tres internos y uno externo). 
- Ciencias de la Educación (seis: dos externos y cuatro internos).

- Ciencias Exactas y Naturales (seis: cuatro externos y dos internos).

- Ciencias Sociales y Humanidades (seis: tres internos y tres externos).

- Sistema de Estudios de Posgrado (cinco: dos internos y tres externos).

- Muestra: 27 personas autoras.

Además, se realizó otro cuestionario (ver Anexo N.2) con la participación de 10 productores académicos de la misma institución.

\section{Resultados y su análisis}

Según el Diccionario de la Real Academia (2001), un autor es toda persona que crea alguna obra literaria, artística o científica susceptible de ser protegida con derechos de autor.

El autor o la autora, en el proceso de producción de material impreso, es un profesional especialista en la materia a quien la universidad que los contrató demanda un servicio. En nuestro caso particular, la elaboración de un material didáctico impreso, que se denomina unidad didáctica, consiste en la selección y organización de la información con el objeto de que el conocimiento científico se convierta en conocimiento (científico) comunicable, disponible para el alumnado.

Con el crecimiento vertiginoso de la información disponible en las últimas décadas, su labor debe centrarse en la utilización de estrategias apropiadas para enseñar a los estudiantes a aprender. Deberá recordar que el aprendizaje está determinado por la existencia de una cultura, que condiciona tanto los contenidos de los cuales los educandos deben apropiarse, como los propios métodos, instrumentos, recursos (materiales y subjetivos) para la apropiación de dicho contenido. (Castellanos, González y Córdoba, 2002, p. 26)

Al revisar las diferentes respuestas de los autores y las autoras a la pregunta a cuál área/escuela/programa pertenece y revisar los archivos correspondientes de las producciones, nos damos cuenta de que cada uno cuenta con saberes vinculados con sus disciplinas. Por ejemplo, los autores y las autoras con títulos correspondientes al área de Ciencias (biólogos, ingenieros agrónomos, ingenieros forestales) estuvieron a cargo de la elaboración de las unidades didácticas de Botánica general: desde los musgos hasta los árboles, Flora de Costa Rica y Genética agrícola, entre otros. 
De la misma forma, se reflexiona sobre las diferentes funciones y tareas que los autores o autoras desarrollan, notamos que el conjunto básico de saberes y competencias se basa en sus diversos saberes y culturas. Así, en el entorno de producción, todo(a) autor(a) debería tener una amplia base de cultura general, estar al tanto del público meta, su nivel y conocimientos, y un saber general del proceso de edición: las etapas y productos que se consiguen en cada una, los profesionales que intervienen, los tiempos que demandan las tareas, el seguimiento editorial, entre otras (Martínez, 2005).

Sin embargo, al convocar a los autores a la reunión de inducción, donde se aclaran los siguientes temas: funciones del Programa de Producción de Material Didáctico (Promade), modelo pedagógico de la UNED, mediación pedagógica, diseño curricular, función de cada integrante del equipo de producción, características de la unidad didáctica impresa en cuanto a contenidos y la edición de su obra. De de los 27 autores entrevistados, solo dos manifestaron conocer sobre edición. Incluso, solo uno es un autor experimentado en diferentes tipos de textos y publicaciones.

Ninguno reveló que se informaba regularmente acerca de teorías sobre la lectura y la escritura, estudios sobre hábitos culturales, análisis del impacto de las transformaciones tecnológicas en las prácticas de lectura y escritura, ni sobre aportes de teorías de la comunicación y la cultura, entre otros; lecturas e investigaciones fundamentales de todo editor académico, Espinoza y Morales (2000).

Lo anterior dificulta el proceso de producción; los autores o autoras, en su mayoría, no siguen las recomendaciones brindadas por el productor académico o la productora académica en la reunión de inducción (ver Anexo N.ํ2).

Como se nota, la función del autor es el resultado de operaciones específicas y complejas que refieren la unidad y la coherencia de la obra, o de una serie de obras, a la identidad de un sujeto construido (Foucault, 1987). Sin embargo, a finales del siglo XVIII y principios del XIX se estableció una fuerte vinculación entre la función del autor y el sistema jurídico e institucional que encerraba, determinaba y articulaba el universo de las obras (Foucault, 1988). Dicha correlación que articula la construcción del autor o la autora y la inscripción de la escritura está relacionada con los derechos y los deberes del autor o la autora.

Los derechos y los deberes son fundamentales para la creatividad humana al ofrecerles incentivos en forma de reconocimiento y recompensas económicas. Este sistema 
de derechos les garantiza a los creadores la divulgación de sus obras sin sospecha de que se realicen copias no autorizadas. A la vez, así se favorece el acceso y la intensificación del disfrute de la cultura, los conocimientos y el entretenimiento en todo el mundo (Foucault, 1988). Los productores académicos y las productoras académicas informan sobre estos derechos y deberes a sus autores y autoras para no incurrir en plagio (Anexo N.․ㄹ 2).

El derecho de autor o la autora protege la forma y no las ideas por más novedosas y brillantes que sean, y otorga derechos de propiedad (morales y patrimoniales) sobre las creaciones literarias, científicas o artísticas. Entiéndase por derechos morales, la expresión de la personalidad del autor (no implica remuneración). (López, 1988, p. 3)

El Derecho Patrimonial se distingue por ser exclusivo, transferible, renunciable, y de una duración limitada (implica remuneración).

No obstante, llama la atención que solo cinco autores conocieran los derechos y los deberes de los autores. En su mayoría, únicamente se limitaban a firmar el contrato. Además, solo los autores y las autoras internos conocían la existencia del reglamento de la UNED.

A continuación, se analizará el papel de la persona encargada de cátedra y el especialista en el proceso de producción de la unidad didáctica escrita.

Los diez productores académicos o productoras académicas entrevistadas manifiestan que los encargados de programa y cátedra revisan que los autores cumplan con los contenidos del curso de acuerdo con la descripción curricular.

Uno de los procedimientos, cuya finalidad es garantizar la calidad científica, pedagógica y ética de los textos, es la evaluación por parte de un especialista de contenido que contribuya al perfeccionamiento, mejoramiento y enriquecimiento de la obra.

El especialista o la especialista de contenido es una persona cuya formación académica, experiencia laboral y especialidad le facultan para emitir criterio acerca de la veracidad de los datos e información, la validez y la vigencia de los contenidos, la calidad del tratamiento del tema, el nivel académico de un material didáctico y la coherencia didáctica de los recursos de mediación utilizados. Su función principal será advertir acerca de sesgos en el enfoque del conocimiento, limitaciones en la argumentación, desactualización en el tratamiento de la materia o bibliografía de referencia y claridad de los planteamientos. 
En general, tanto las personas autoras como las productoras declararon estar conformes con el papel del especialista en la revisión de su obra.

Se detalle, de seguido, cuáles son los errores frecuentes de los autores o autoras según las revisiones de los diferentes miembros del equipo de producción encargado de cátedra, encargado de programa, especialista, filólogo y productor académico.

En general, conforme avanza el proceso de producción, se detectaron faltas graves en la escritura de los materiales. Las competencias de escritura de los autores y las autoras (que suelen ser especialistas en la materia sobre la que escriben, pero a menudo no son escritores expertos) son muy escasas. Espinoza y Morales (2000) han detectado problemas en el proceso de enseñanza aprendizaje, que existen desde el colegio en el desarrollo de la lectura y la escritura de los alumnos. Tanto el productor académico como el filólogo deben invertir mucho tiempo en la revisión de la escritura de estos textos.

En términos generales, algunos de los errores frecuentes del autor cuando escribe un material impreso para enseñar a distancia, según los registros de los productores académicos son:

- Falta concordancia gramatical.

- Falta información para entender lo que se expresa en el escrito.

- Las citas y referencias bibliográficas no son las adecuadas y muchas veces están incompletas.

- Falta validez y legitimidad de las fuentes.

- Errores de digitación y ortográficos.

- Mala postulación de los cuadros y las figuras.

- Falta de fuentes consultadas.

- Faltan actividades de aprendizaje.

- No existe progresión de ideas y concatenación de apartados, párrafos y secciones en todo el escrito.

- Uso inadecuado de los signos de puntuación.

- No se toma en cuenta al público meta, su nivel ni sus posibles conocimientos.

En general, estos errores coinciden con la experiencia de los autores al escribir materiales didácticos para publicar; en la mayoría de los casos, 19 de 27, era la primera vez que escribían una unidad didáctica. 
Asimismo, en los casos más graves, 4 de 27, el trabajo sobre los originales adquiere las características de una reescritura o supone, al menos, una intervención sustantiva sobre los textos: modificación en el orden de exposición de las ideas, cambios en la titulación, reposición de información faltante, eliminación de información no pertinente, ajustes en la progresión de la información, etc. Actualmente, si esto sucede, según las políticas de la oficina de Promade, se procede a rescindir el contrato.

El conjunto de procedimientos apoyados en las técnicas de enseñanza se denomina estrategia didáctica. Su objetivo es llevar a buen término la acción didáctica, es decir, alcanzar los objetivos de aprendizaje. Las técnicas son procedimientos didácticos que ayudan a realizar una parte del aprendizaje que se facilita con la estrategia. Las actividades son parte de las técnicas y son acciones específicas que facilitan la ejecución de la técnica. Son flexibles y permiten ajustar la técnica a las características del grupo (Bruner, 1988 y Zabalza, 1991).

En nuestro caso, los autores de las unidades didácticas facilitaron, como estrategia didáctica, el autoaprendizaje por medio del uso de los objetivos o propósitos de aprendizaje, los resúmenes, las actividades de aprendizaje, las ilustraciones, preguntas intercaladas, analogías, mapas conceptuales y el uso de estructuras textuales para facilitar el discurso escrito. Igualmente, entre las técnicas presentaron la investigación y el análisis de información, la preparación de ensayos, las tareas individuales, las investigaciones y los proyectos. Todo lo anterior lo lograron con el apoyo del equipo de producción, en especial la guía del productor académico o la productora académica.

Las estrategias didácticas utilizadas constituyen elementos claves del proceso de enseñanza aprendizaje, por el volumen de información que facilita al(la) tutor(a) y por las consecuencias para el alumnado, el sistema educativo donde está integrado y la sociedad. Tales estrategias no constituyen una simple actividad técnica, sino que establecen un elemento clave en la calidad de los aprendizajes, condicionan la profundidad y el nivel. Sin embargo, con el fin de determinar si se cumplió con este objetivo, es necesario recomendar la validación de las unidades didácticas por parte de los alumnos y los miembros del equipo de producción. 


\section{Conclusiones}

Las investigaciones que informan y alimentan este artículo son de naturaleza cualitativa y se desarrollan con grupos de conversación, a fin de respetar y reconocer tanto el conocimiento o saber del autor universitario respecto del proceso de enseñanza aprendizaje a distancia, como la naturaleza compleja y dinámica de la fase interactiva, en la que el alumnado y el tutor o la tutora interactúan con la mediación de múltiples condiciones en el tipo de contenido de la unidad didáctica impresa.

Según Bok (1992), la universidad se ha caracterizado, tradicionalmente, por la ejecución de tres tareas primordiales: producción, transmisión y aplicación de conocimientos, sean estos definidos como saberes, disciplinas, tecnologías, teorías, diseños, entre otros. En la educación a distancia, una gran parte de estas tres tareas está a cargo de un equipo de producción y, en nuestro caso analizado, la UNED, las unidades didácticas impresas están escritas por autores universitarios o autoras universitarias.

Los cambios en la naturaleza del conocimiento, su uso y su transmisión introducen importantes retos en el desarrollo de las instituciones públicas de educación superior y en el campo académico universitario. Este contexto de relación es fundamental para comprender la dinámica de las universidades a distancia en el futuro próximo.

Cada autor, con sus experiencias y saberes provenientes de diferentes disciplinas, construye, como en toda profesión, su recorrido singular (Martínez, 2005). En cambio, en nuestra investigación, el trabajo de cada autor o autora, en conjunto con el productor académico o productora académica, se sustenta en un conocimiento exhaustivo de los mecanismos de producción de significado mediante textos e imágenes y de lectura de textos especializados (a menudo acompañados de gráficos, cuadros, mapas y fotografías), los cuales se dirigen a un público meta: el alumnado a distancia. Sin embargo, en el mundo de habla hispana no hay, hasta ahora, un ámbito de formación superior que se ocupe de la enseñanza de esta especialidad o modalidad.

Como se anotó, el proceso de escribir es complejo. Adecuar la información a los conocimientos previos del lector y al propósito de lectura supone, muchas veces, eliminar información necesaria, brindar más o mejores ejemplos, prever problemas en la utilización de los materiales descritos en la obra y sugerir formas de ampliar la información. Y, si unido a lo anterior, el autor no acata los lineamientos establecidos por el equipo de producción, la escritura de la unidad didáctica se vuelve infructuosa. 
El tiempo y el conocimiento que debe invertir un autor en escribir una unidad didáctica son exhaustivos porque la calidad científica y académica de los contenidos de los materiales didácticos de la UNED deben garantizar una educación profesional de alto nivel, basada en conocimientos veraces, actualizados, éticos y adecuados para el nivel educativo del estudiantado.

La tarea de editar es muy compleja. En la mayoría de los casos al no contar con una profesión especializada para este fin, algunos de los autores agradecieron la ayuda imprescindible de los lineamientos establecidos por Promade.

A pesar del esfuerzo y el tiempo que invierten los autores o las autoras en la producción de su obra, no existe motivación alguna para conocer sus derechos y sus deberes. Algunos manifestaron que eran más sus deberes que sus derechos. Otros, que el pago simplemente no representaba para ellos un hecho importante; escribían solo por el prestigio de hacerlo.

El equipo de producción, en especial los encargados de cátedra, manifestó que el diseño y empleo de objetivos e intenciones de enseñanza, actividades de aprendizaje, preguntas insertadas, ilustraciones, modos de respuesta, organizadores anticipados, redes semánticas, mapas conceptuales y esquemas de estructuración de textos, entre otros, facilitaron el proceso que ocurre a partir de la interacción de los dos colectivos (el que enseña y el que aprende) en espacios didácticos preparados con intención formativa, como el caso de las unidades didácticas escritas de la educación a distancia.

Asimismo, el autor o la autora en el proceso de análisis y de reelaboración de la materia por enseñar, consistente en la selección y organización de la información, a fin de que el conocimiento científico se convierta en conocimiento (científico) comunicable, disponible para el alumnado.

Con el fin de verificar el éxito en el aprendizaje de los estudiantes de la educación a distancia, mediante las unidades didácticas impresas y de los procedimientos y lineamientos establecidos por Promade, se recomienda su validación. Algunas unidades ya han sido validadas y demuestran estar acordes con su objetivo principal de creación: facilitar el proceso de enseñanza aprendizaje a los alumnos de educación a distancia. También con algunas unidades didácticas, los autores han ganado premios en nivel nacional, por ejemplo: el Premio Nacional Aquileo J. Echeverría 2011 con la unidad didáctica Botánica general. Desde los musgos hasta los árboles, del autor Gustavo Vargas. 


\section{Referencias}

Amador Bautista, Rocío. (2001). Educación y formación a distancia. México: Universidad de Guadalajara.

Arends, Richard. (2007). Aprender a enseñar. México: McGraw-Hill.

Bok, Derek. (1995). Educación Superior. Buenos Aires: El Ateneo.

Bruner, Jerome. (1988). Desarrollo cognitivo y educación. Madrid: Morata.

Bruner, Jerome. (1988). The process of education. Cambridge: Harvard University Press.

Bruner, Jerome. (1997). La educación puerta de la cultura. Madrid: Visor.

Castellanos Simons, Doris; González Maura Viviana y Córdoba, María Dolores. (2002). Aprender y enseñar en la escuela. La Habana: Editorial Pueblo y Educación.

Coover, Robert. (21 de junio de 1992). The end of books. Recuperado de http://www.nytimes.com/books/98/09/27/specials/coover-end.html

Del Mastro, Cristina (2003). El aprendizaje estratégico en la educación a distancia. Lima: Fondo editorial PUCP. Serie: Cuadernos de Educación.

Díaz Barriga, Frida y Hernández Rojas, Gerardo. (1999). Estrategias docentes para un aprendizaje significativo. México: McGraw Hill.

Escamilla, Amparo. (1993). Unidades didácticas: una propuesta de trabajo de aula. Barcelona: Edelvives.

Espinoza, Norelkys y Morales, Óscar. (2000). El desarrollo de la lectura y escritura en la universidad: una experiencia de integración docente. FOULA, 1(1), 74-81.

Foucault, Michel. (1987). El orden del discurso. Barcelona: Paidós.

Foucault, Michel. (1988). Las palabras y las cosas. México: Siglo XXI.

Holmberg, Börje. (1995). Theory and Practice of Distance Education. Londres: Rouledge.

López, Flor. (1998). Los derechos de autor en Costa Rica. Revista de la escuela de Bibliotecología, 16(1), 1-7. Universidad Nacional.

Manual del productor académico. (1982). UNED, Dirección de Producción Académica.

Martínez de Sousa, José (2005). Manual de edición y autoedición. Madrid: Ediciones Pirámide.

Piccolini, Patricia. (2002). La edición técnica. En: Leandro de Sagastizábal y Fernando Esteves Fros (comps.). El mundo de la edición de libros. Buenos Aires: Paidós. 
Pozo, Juan; Scheuer, Nora; Pérez Echeverría, María; Mateos, Mar; Martín, Elena y de la Cruz, María (Eds.) (2006). Las concepciones de profesores y alumnos sobre el aprendizaje y la enseñanza. Barcelona: Graó.

Williams, Peter. (2000), Defining distance education roles and competencias for higher education institutions: A computer-mediaded delphi study. Unpublished doctoral dissertation, Texas: A y M University, Educational Human Respurse Development Departament, Collage Station, TX.

Williams, Peter. (2003), Roles and Competencies for Distance Education Programs in Higher Education Institutions. The American Journal of Distance Education 17(1), 45-57.

Zabalza, Miguel Ángel. (1991). Los contenidos. Diseño y desarrollo curricular. Madrid: Narcea. 


\section{Anexo N.․ 1}

\section{Cuestionario para los autores(as)}

El presente cuestionario tiene como objetivo conocer su percepción como autor o autora acerca de la escritura de los materiales didácticos de la UNED; la información se considerará en una investigación particular relacionada con el papel de los autores(as), con la cual se pretende apoyar un artículo por publicarse en una revista académica.

1. ¿A qué área/escuela/programa pertenece?

2. ¿Fue convocado a una reunión inicial o de inducción?

3. ¿Recuerda qué se comentó en esta reunión? ¿Utilizó las recomendaciones que le sugirieron?

4. ¿Es la primera vez que escribe? ¿Posee usted conocimientos de edición?

5. ¿Posee usted hábitos de lectura y su escritura y su impacto en las transformaciones tecnológicas actuales?

6. ¿Se le informaron de sus deberes y derechos como autor?

7. ¿Sabía usted de la existencia de un reglamento para autores de la UNED?

8. ¿Cuál fue el proceso de escritura que siguió?

9. ¿Analizó la descripción curricular?

10. ¿Elaboró un plan de obra?

11. ¿Elaboró un cronograma?

12. ¿Elaboró actividades de aprendizaje?

13. ¿Eligió una estrategia didáctica y evaluativa?

14. ¿Recibió recomendaciones del encargado(a) de cátedra, de programa, del especialista y del productor(a) académico(a)?

15. ¿Entregó el material según se había establecido?

16. Mencione las estrategias didácticas utilizadas en la producción de su obra.

17. ¿Anteriormente había tenido alguna experiencia como autor o autora?

18. ¿Al escribir, consideró al público meta, su nivel y los posibles conocimientos que tuvieran?

19. ¿Cómo cree usted que se ve la figura del autor en la UNED?

20. ¿Cuáles fueron sus errores más comunes a la hora de escribir la unidad didáctica, según los criterios del equipo de producción? 


\section{Anexo N.ㅇ 2}

\section{Cuestionario para los productores o productoras}

El presente cuestionario tiene como objetivo conocer su percepción como productor académico o productora académica acerca de la escritura de los materiales didácticos de la UNED; la información se considerará en una investigación particular relacionada con el papel de los autores, con la cual se pretende apoyar un artículo por publicarse en una revista académica.

1. ¿Los autores o las autoras que han participado en las producciones asignadas por su jefatura cuentan con saberes vinculados a la disciplina correspondiente?

2. ¿Considera usted que los autores o las autoras deben poseer conocimientos de edición? ¿Por qué?

3. ¿Alguno de sus autores o autoras lee y analiza el impacto de las transformaciones tecnológicas en las prácticas de lectura y escritura, aparte de la teoría de la comunicación y la cultura?

4. Los autores o las autoras a su cargo siguen los lineamientos y procedimientos suministrados en la reunión de inducción. Explique.

5. ¿Les informó sobre los derechos y los deberes de los autores o autoras?

6. ¿Cuál fue el papel del encargado (a) de cátedra y del especialista durante el proceso de producción?

7. Enumere los errores más frecuentes de los autores o las autoras durante la producción de la unidad didáctica impresa.

8. Mencione las estrategias didácticas utilizadas en la escritura de las unidades didácticas impresas. 